\title{
Avaliação eletromiográfica dos músculos das costas no ciclismo: um estudo de caso
}

\author{
Elisandro de Assis Martins ${ }^{1}$, Frederico Dagnese ${ }^{2}$, Álvaro Sosa Machado³, \\ Emmanuel Souza da Rocha ${ }^{4}$, Carlos Bolli Mota ${ }^{5}$, Felipe Pivetta Carpes ${ }^{6}$
}

\begin{abstract}
RESUMO
Neste estudo quantificamos a atividade elétrica neuromuscular de músculos das costas de um ciclista treinado sem história de dor lombar. A sua bicicleta foi anexada a um simulador de ciclismo. Ele pedalou em intensidade entre $70 \%$ e $80 \%$ de seu pico de potência, até exaustão. Dados eletromiográficos foram analisados considerando o valor médio dos quadrados para representar a magnitude da ativação muscular. Houve um aumento da ativação muscular para todos os músculos. Trapézio descendente (2,4\%) e iliocostal (31,77\%) do lado não-preferido tiveram aumento da atividade muscular, já o longuíssimo do tórax $(11,33 \%)$ teve aumento no lado preferido. 0 aumento da ativação muscular sem ocorrência de dor lombar sugere um efeito de fadiga. O protocolo foi útil para induzir fadiga de músculos lombares e pode ser útil para investigar desequilíbrios musculares frequentemente associados à dor lombar e fraqueza de quadril.
\end{abstract}

Descritores: Dor Lombar; Ciclismo; Fadiga; Exercício; Coluna; Ativação Muscular.

\section{Electromyographic assessment of back muscles in cycling: a case study}

\begin{abstract}
Here we quantified the electric neuromuscular activity of selected back muscles of a trained mountain bike cyclist without history of low back pain. For data collection, cyclist' own bicycle was attached to a cycle simulator. The cyclist cycled at workload set between $70 \%$ and $80 \%$ of peak power output until exhaustion. Electromyography data was analyzed considering the root mean square values computed to represent the overall magnitude of activation. There was a general increase in the muscle activation for all the muscles analyzed. This behavior was remarked for trapezius descendens $(2.4 \%)$ and iliocostalis $(31.77 \%)$ in the non-preferred body side, whereas the longissimus increased activation (11.33\%) in the preferred side. The increase in muscle activation without report of low back pain suggests that effects of fatigue were observed. The protocol was useful to elicit fatigue in back muscles and can serve to investigate muscular imbalances usually associated with low back pain and hip weakness.
\end{abstract}

Descriptors: Back Pain; Cycling; Fatigue; Exercise; Spine; Muscle Activation.

\footnotetext{
${ }^{1}$ Especialista em Atividade Física, Desempenho Motor e Saúde pela Universidade Federal de Santa Maria (UFSM), Santa Maria, RS, Brasil.

${ }^{2}$ Mestre em Ciências do Movimento Humano pela Universidade Federal do Rio Grande do Sul (UFRGS), Porto Alegre, RS, Brasil.

${ }^{3}$ Acadêmico de Fisioterapia na Universidade Federal do Pampa (UNIPAMPA), Uruguaiana, RS, Brasil.

${ }^{4}$ Graduado em Fisioterapia pela Universidade Federal do Pampa (UNIPAMPA), Uruguaiana, RS, Brasil.

${ }^{5}$ Doutor em Ciência do Movimento Humano pela Universidade Federal de Santa Maria (UFSM), Santa Maria, RS, Brasil.

${ }^{6}$ Doutor em Ciências do Movimento Humano pela Universidade Federal do Rio Grande do Sul (UFRGS), Porto Alegre, RS, Brasil.
} 


\section{Introduction}

The effects of muscle fatigue on cycling performance have been extensively documented, especially regarding central and peripheral factors influencing performance ${ }^{1}$. When fatigue effects become remarked, cyclists tend to decrease the range of motion for hip extension and ankle flexion ${ }^{2}$, which might influence pelvis positioning and consequently the activation of back muscles leading to pain. The low back pain has been associated with impairment of performance, and commonly observed between cyclists. Its origin is considered multi-factorial, which limits the prevention.

The trunk position has been reported as determinant for spine discomforts and pain occurrence during prolonged cycling training and/or competitions ${ }^{3}$. The pain can result from the usual trunk position of the athletes ${ }^{4,5}$. Indeed, pain can influence muscle mechanics properties (e.g., force-length and force-velocity muscle relations) and the patterns of muscular recruitment of many upper and lower extremity muscles during pedaling ${ }^{6}$.

The sustained contraction of low back muscles during prolonged cycling trials provides stability for pelvis and hip joints during pedaling, and the inadequate strength and endurance of the lumbar muscles lead to premature fatigue and low back pain ${ }^{7}$. Additionally, it increases the risk of herniated disc during years of practice ${ }^{8}$. To avoid stop training due to injury, increase the strength and endurance of back muscles can be a satisfactory strategy ${ }^{9}$.

The magnitudes and patterns of muscle activation among the muscles acting as primary motors for the movement can be estimated by means of surface electromyography (EMG). The submaximal prolonged cycling elicits fatigue of back muscles during pedaling, which was suggested as more often among people with low back pain history ${ }^{10}$. Additionally, cyclists with non-specific chronic low back pain present increased lower lumbar flexion during cycling, which contributes to low back pain ${ }^{11}$.

Effects of prolonged cycling on lower limbs muscle activation have been described ${ }^{12}$, but the muscle activation of the back muscles during prolonged cycling still needs further attention. During a prolonged cycling trial, it can be possible to check whether changes in muscle activation of back muscle depend on the process of muscle fatigue per se or have some association with the onset of low back pain/discomfort during exercise. Therefore, the purpose of this case study was to quantify bilateral muscle activation of three muscles of the spine region - erector spinae (longissimus and iliocostalis) and trapezius descendens (upper) - in one trained cyclist without history of low back pain during cycling to exhaustion.

\section{Methodology}

$\underline{\text { Subject }}$

This study was approved by the local institution ethic committee (IRB\# 23081.013958200707). A male mountain bike (MTB) trained cyclist 32 years old, body mass $75 \mathrm{~kg}$, and height $1.88 \mathrm{~m}$, without previous history of musculoskeletal injuries or low back pain, presenting weekly training volume about $300 \mathrm{~km}$ and thirteen years of experience in competition was voluntary for this study. The right body side was his preferred to perform motor actions such was writing something and kicking a ball. The subject agreed with all procedures by signing a consent term and answered a questionnaire informing the history of pain and injuries while cycling.

\section{Experimental design}

The cyclist brought his own bicycle (Trek, MTB, Alpha Black Aluminum 6500, USA) to the laboratory for the testing. The bicycle was attached to a cycle simulator with electromagnetic brakes (CompuTrainer Pro Lab3D, Racer Mate Inc, Seattle, USA). The pedaling cadence and workload were continuously controlled by the cycle simulator software and the heart rate was recorded throughout the entire tests using a cardiac monitor. The laboratory room was maintained with controlled temperature $\left(22 \pm 1^{\circ} \mathrm{C}\right)$. Two tests were performed. An interval period of 1 week was permitted between these two tests: incremental maximal and submaximal workload tests. 
Incremental maximal and submaximal workload tests

A progressive maximal test was performed to determine the peak power output (PPO). After 5 minutes of warm up with at workload of $100 \mathrm{~W}$, cycling workload was increased by $30 \mathrm{~W}$ every minute, until exhaustion. Exhaustion was defined by the incapacity to maintain pedaling cadence higher than $90 \mathrm{rpm}$. The PPO was considered as the workload of the last stage fully completed. In the subsequent week, the athlete performed a submaximal test when data from muscle activation were recorded. The submaximal test started with workload set at $100 \mathrm{~W}$ during a period of 10 min (also serving for warming up) and then was increased to the target intensity between $70 \%$ and $80 \%$ of PPO. The cyclists should keep pedaling at this intensity of $70-80 \%$ of PPO until exhaustion. The test lasted about 2 hours.

\section{Muscle activation assessment}

The electric neuromuscular activity was monitored by means of surface electromyography. Pairs of electrodes (Ag$\mathrm{AgCl}$ ) with diameter of $20 \mathrm{~mm}$ in bipolar configuration were attached bilaterally on the shaved and cleaned skin over erector spinae (longissimus and iliocostalis) and trapezius descendens (upper). Skin was cleaned and skin impedance was checked according to SENIAM recommendations for skin preparation and electrodes positioning ${ }^{13}$. For reduction of artifact movement adhesive tapes were used during the data collection to keep the wires with minimal movements.

The EMG signals were amplified and recorded at a sampling rate of $2000 \mathrm{~Hz}$ with 14 bit resolution using a Lynx System (Lynx 1200, Lynx Technologies, São Paulo, BRL). The raw EMG signals were smoothed with a $5^{\text {th }}$ order band pass Butterworth digital filter at cut-off frequency of $10-500 \mathrm{~Hz}$. After full-wave rectification and off-set correction, the onset and offset of EMG activity were determined by the signal increase/decrease two standard deviations above the baseline value recorded at rest between each EMG burst ${ }^{14}$. The EMG signals were acquired after the subject resting in a seated position by 5 minutes, in the final stage of the first 10 min warm up and then during 20 seconds every 5 minutes during the entire submaximal test. The RMS value was calculated considering a window size of $40 \mathrm{~ms}^{15}$ and used as an indicative of the magnitude of muscle activation ${ }^{16}$. The RMS found at rest was considered for RMS normalization. Data processing was conducted using Origin 6.0 (Originlab Corp., Northampton, MA, USA).

\section{Statistical Analysis}

Descriptive statistics for mean and standard-deviation were applied to quantify muscle activation of trapezius descendentsm longissimus, and iliocostalis muscles every 5 minutes during the submaximal test. Considering the muscle activation over time, the patterns of activation magnitude changes during the test was analyzed by means of analysis of linear regression considering the curve slope (angular coefficient) when plotting RMS vs. time. A significance level of 0.05 was considered.

\section{Results and Discussion}

No affirmative answers concerning low back pain, pelvic, spine or lower leg discomforts were reported by the cyclist during the trials. He reached maximal heart rate $(\mathrm{HR})$ of $187 \mathrm{bpm}$ and maximal power output of $391 \mathrm{~W}$ during the incremental maximal test. For the submaximal test, the mean target intensity was set at $293 \mathrm{~W}$ (75\% of PPO), with a range between $274 \mathrm{~W}(70 \%$ of PPO) and $313 \mathrm{~W}$ ( $80 \%$ of PPO), and pedaling cadence of $97 \pm 3 \mathrm{rpm}$. The mean and maximal HR during the submaximal test was $143 \pm 14$ and $164 \mathrm{bpm}$, respectively. The cyclist had continuously visual feedback of time, $H R$, power output and pedaling cadence during the trial. The RMS values obtained for trapezius descendents (Figure 1), longissimus (Figure 2) and iliocostalis (Figure 3) are represented below. The submaximal trial lasted 112 minutes. 
Figure 1- RMS values of trapezius descendents muscle during the submaximal cycling trial.

Continuous and dotted lines represent signals from the preferred and non-preferred side, respectively.
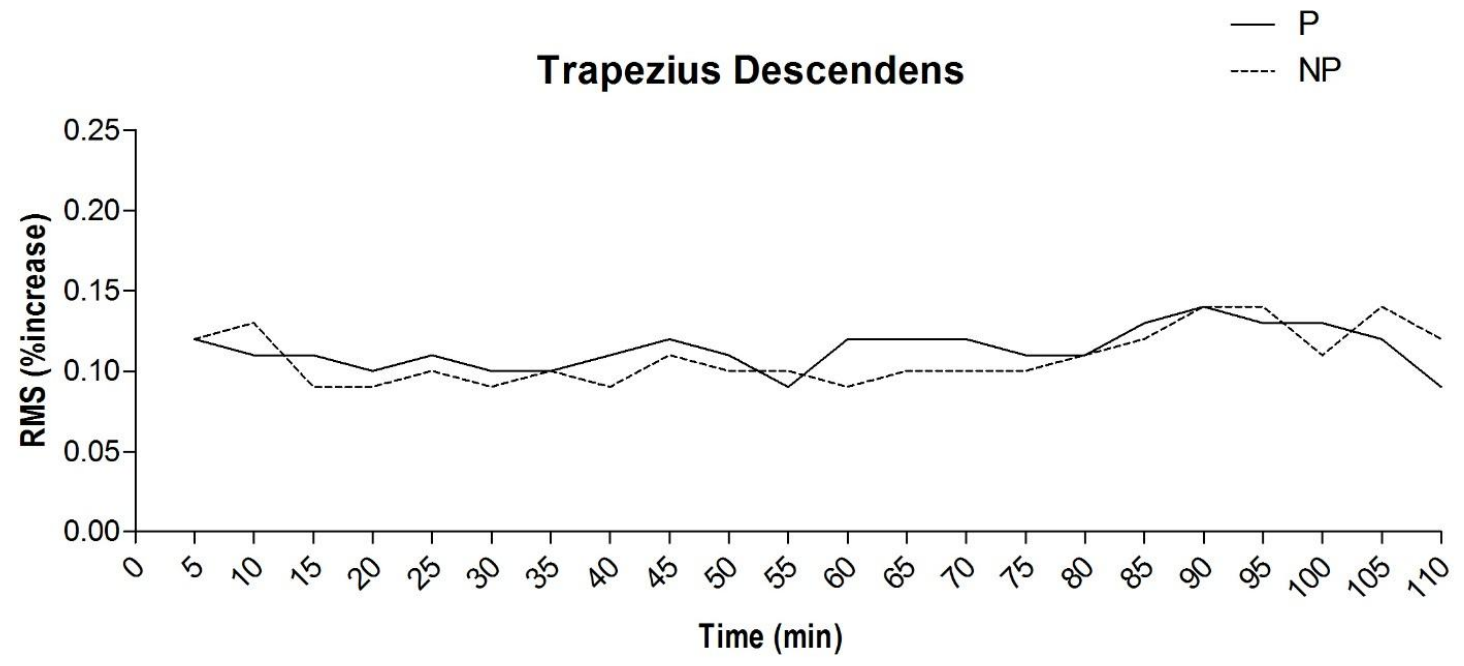

Figure 2 - RMS values of longissimus muscle.

Continuous and dotted lines represent signals from the preferred and non-preferred side, respectively.
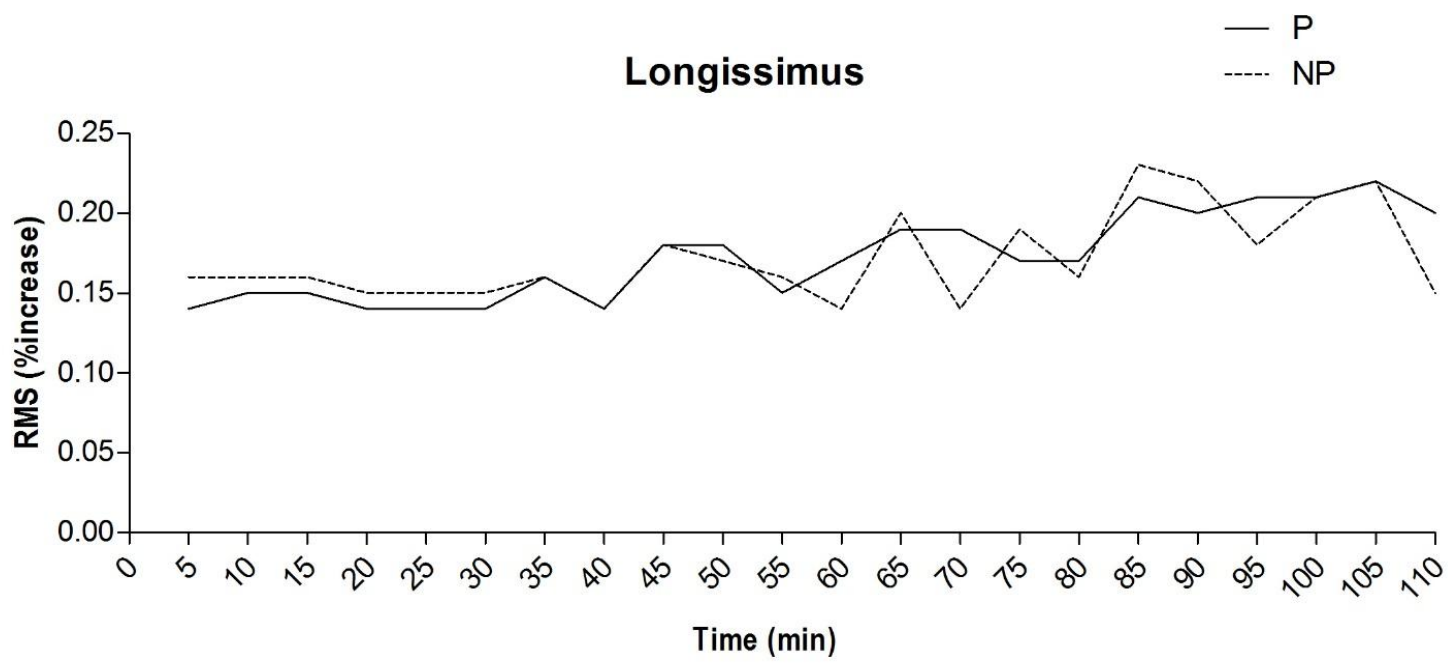

Figure 3. RMS values of iliocostalis muscle.

Continuous and dotted lines represent signals from the preferred and non-preferred side, respectively.
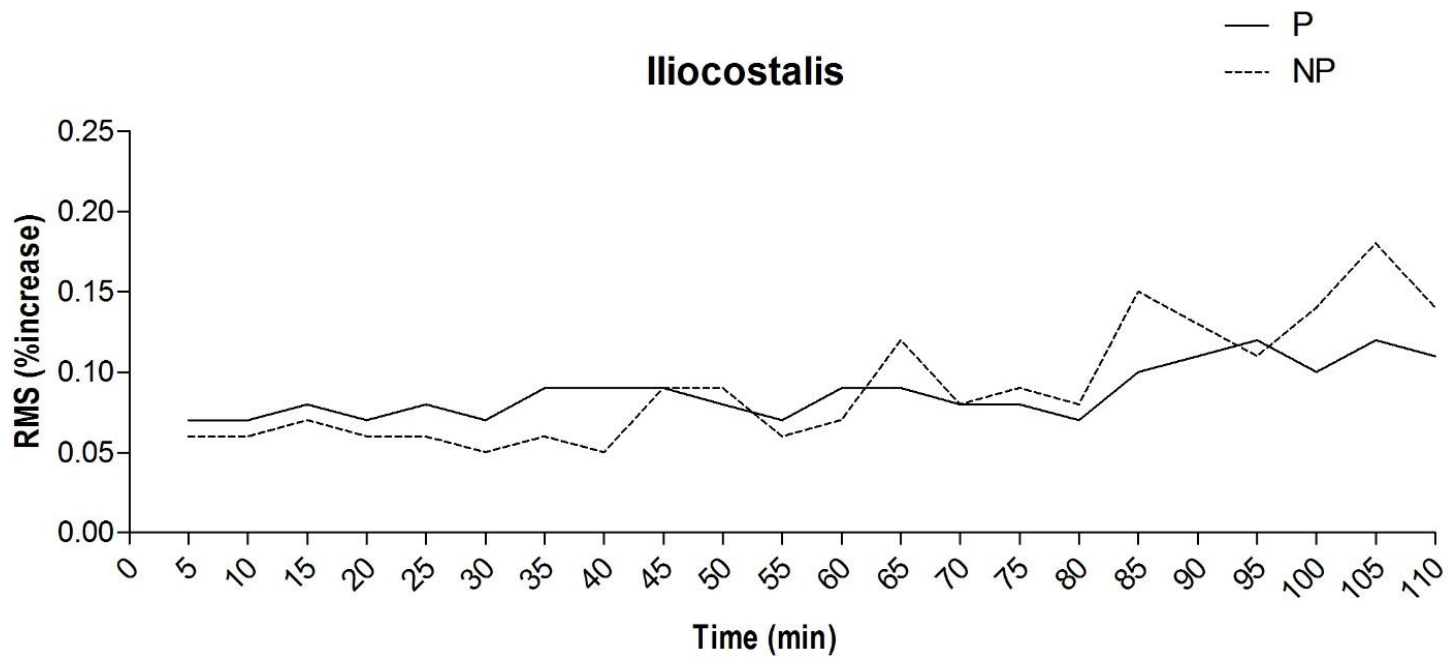
The linear regression results are summarized in the table 1. For the trapezius descendens and iliocostalis muscles, the angular coefficients were higher in the non-preferred side, suggesting higher activation and more remarked index of fatigue during the exercise. However, in the longissimus muscle, changes in RMS were more pronounced in the preferred side. The highest correlation coefficients between RMS and total time of exercise were found in the longissimus e iliocostalis muscles (table 1).

Table 1 - Linear regression for RMS vs. time of exercise.

Angular and determination coefficients obtained from linear regression for RMS ( $\mu \mathrm{V})$ vs. time of exercise for the trapezius descendens (TD), longissimus (Long) and iliocostalis (llioc) muscles in the preferred (P) and non-preferred (NP) body side.

Significant values were considered when $p<0.05$

\begin{tabular}{c|c|c|c|c|c|c}
\hline Analysis & TD P & TD NP & Long P & Long NP & Ilioc P & llioc NP \\
\hline $\begin{array}{c}\text { Angular } \\
\text { Coefficient }\end{array}$ & 0.52 & 0.92 & 2.68 & 1.59 & 2.43 & 8.31 \\
\hline $\begin{array}{c}\text { Determination } \\
\text { Coefficient }\end{array}$ & 0.11 & 0.21 & 0.73 & 0.33 & 0.56 & 0.69 \\
\hline $\begin{array}{c}\text { Coefficient of } \\
\text { Correlation }\end{array}$ & 0.33 & 0.46 & $0.86^{*}$ & $0.58^{*}$ & $0.75^{*}$ & $0.83^{*}$ \\
\hline
\end{tabular}

In this case study we quantified the level of activation in back muscles during prolonged cycling. One trained cyclist without history of low back pain performed the trials. The muscles evaluated have an important role for trunk stabilization while sustaining the pelvis over the bicycle saddle ${ }^{17}$; therefore, they are important when addressing trunk stabilization and low back pain during cycling. The characteristics of activation for these muscles, as the increase of mean power frequency, have been suggested related to fatigue in short duration tests (30 min) involving low back pain subjects ${ }^{10}$. During the prolonged submaximal trial, discomforts experimented by the cyclist were always related to saddle. He did not report any episode of spine pain during the exercise. However, despite of the no complain about pain, we observed increase in the magnitude of activation (RMS) during the trial.

The increase in the muscle activation over time is expected due to mechanisms of fatigue, in which additional motor units are recruited as an attempt to maintain the expected level of force ${ }^{18-20}$. Additional factors such as non-linear patterns of fatigability in lumbar extensors ${ }^{21}$, low flexibility, and poor physical conditioning can also accelerate the fatigue processes increasing tension in the spine ${ }^{22}$. Considering the slope of RMS curve over the time, our data showed that the non-preferred side presented higher inclination when compared to the preferred side. Further studies are required to clarify these results, but they could suggest that there are some imbalances in back muscles activation even for a subject without low back pain.

Cyclists are usually oriented to sustain the physiological curvature of their spine while cycling. However, as long as the trunk is positioned forward, a lower level of flexibility of posterior thigh muscles combined with the saddle type (mainly in the saddles with plane surface) acts directly to hamper the anterior pelvic tilt ${ }^{23,24}$.Therefore, the position on the bike may lead to increased pressure on the anterior region of the vertebra and stretches the ligaments from posterior region, which implies discomforts and low back pain ${ }^{22}$. It would contribute to increase muscle activation aiming at sustenance of the spine posture throughout the exercise. Furthermore, reductions in the level of proprioception have been observed for spine as the trunk is positioned forward, which conduct to deficits in coordination and dynamic stability, increasing the risks of injuries in the low back ${ }^{25}$.

In a short duration test (30 $\mathrm{min}$ ) a significant increase in the mean power frequency for right erector spinal muscle was observed. The subject of our study reported their right side as preferred, but the higher levels of muscle activation were observed in the opposite side. If the contra-lateral side acts to stabilize the spine, based on handlebar applied forces ${ }^{26}$, and the athlete had not low back pain, it is possible that the lumbar muscles of preferred side could be more resistant to the fatigue, which would result from prolonged training.

The differences in the magnitude of activation can rely on upper or lower limb asymmetries in the force applied on handlebars and pedals, respectively ${ }^{26,27}$. Asymmetries in force production of muscles that cross or act close to the hip are suggested to cause muscle unbalances and low back pain ${ }^{28}$. Van Hoof, Volkaerts ${ }^{11}$ observed increased lumbar spine flexion in subjects with low back pain. The occurrence of low back pain is an important issue for assessment of back muscles, as it was reported that subjects with low back pain presented an asymmetric pattern of activation of multifidus muscle when compared to the no-pain group ${ }^{29}$. 


\section{Final Considerations}

A prolonged submaximal cycling exercise increases the activation of back muscles, without interaction with low back pain. The differences between preferred and non-preferred body sides suggest imbalances in muscle recruitment that may contribute to asymmetries in force transfer from back to pelvic, which require further studies. The protocol described here was useful to elicit fatigue in back muscles of a pain-free athlete and can serve to investigate muscular imbalances usually associated with low back pain and hip weakness.

\section{Conflict of interest}

None

\section{Bibliographic References}

1. Boyas $S$ and Guevel A. Neuromuscular fatigue in healthy muscle: underlying factors and adaptation mechanisms. Ann Phys Rehabil Med. 2011; 54: 88-108.

2. Sayers MG, Tweddle AL, Every $\mathrm{J}$ and Wiegand A. Changes in drive phase lower limb kinematics during a 60 min cycling time trial. J Sci Med Sport. 2012; 15: 169-74.

3. Burnett A, O'Sullivan P, Ankarberg L, et al. Lower lumbar spine axial rotation is reduced in end-range sagittal postures when compared to a neutral spine posture. Man Ther. 2008; 13: 300-6.

4. Clarsen B, Krosshaug T and Bahr R. Overuse injuries in professional road cyclists. Am J Sports Med. 2010; 38: 2494-501.

5. Purepong N, Jitvimonrat A, Boonyong S, Thaveeratitham $P$ and Pensri P. Effect of flexibility exercise on lumbar angle: a study among non-specific low back pain patients. J Bodyw Mov Ther. 2012; 16: 236-43.

6. Chapman AR, Vicenzino B, Blanch P, Knox JJ, Dowlan S and Hodges PW. The influence of body position on leg kinematics and muscle recruitment during cycling. J Sci Med Sport. 2008; 11: 519-26.

7. Moffroid MT. Endurance of trunk muscles in persons with chronic low back pain: assessment, performance, training. J Rehabil Res Dev. 1997; 34: 440-7.

8. Adams MA, Bogduk N, Burton K and Dolan P. The Biomechanics of Back Pain. In: Livingston EC, (ed.). Elsevier Church Livingston, 2006.

9. Abt JP, Smoliga JM, Brick MJ, Jolly JT, Lephart SM and Fu FH. Relationship between cycling mechanics and core stability. J Strength Cond Res. 2007; 21: 1300-4.

10. Srinivasan $\mathrm{J}$ and Balasubramanian V. Low back pain and muscle fatigue due to road cycling-An sEMG study. J Bodyw Mov Ther. 2007; 11: 260-6.

11. Van Hoof W, Volkaerts K, O'Sullivan K, Verschueren S and Dankaerts W. Comparing lower lumbar kinematics in cyclists with low back pain (flexion pattern) versus asymptomatic controls--field study using a wireless posture monitoring system. Man Ther. 2012; 17: 312-7.

12. Hug F and Dorel S. Electromyographic analysis of pedaling: a review. J Electromyogr Kinesiol. 2009; 19: $182-98$.

13. De Nooij R, Kallenberg LA and Hermens HJ. Evaluating the effect of electrode location on surface EMG amplitude of the m. erector spinae p. longissimus dorsi. J Electromyogr Kinesiol. 2009; 19: e257-66.

14. Hodges PW and Bui BH. A comparison of computer-based methods for the determination of onset of muscle contraction using electromyography. Electroencephalogr Clin Neurophysiol. 1996; 101: 511-9.

15. Neptune RR, Kautz SA and Hull ML. The effect of pedaling rate on coordination in cycling. J Biomech. 1997; 30: 1051-8. 16. Moritani T, Muro M, Kijima A and Berry MJ. Intramuscular spike analysis during ramp force output and muscle fatigue. Electromyogr Clin Neurophysiol. 1986; 26: 147-60.

17. Basmajian JV and Luca CJD. Muscles Alive: Their Functions Revealed by Electromyography. 5 ed.: Williams \& Wilkins, 1985. 18. Christensen H, Sogaard K, Jensen BR, Finsen L and Sjogaard G. Intramuscular and surface EMG power spectrum from dynamic and static contractions. J Electromyogr Kinesiol. 1995; 5: 27-36.

19. deVries HA, Moritani T, Nagata A and Magnussen K. The relation between critical power and neuromuscular fatigue as estimated from electromyographic data. Ergonomics. 1982; 25: 783-91. 
20. Miyashita M, Kanehisa H and Nemoto I. EMG related to anaerobic threshold. J Sports Med Phys Fitness. 1981; 21: 209-17. 21. Beneck GJ, Baker LL and Kulig K. Spectral analysis of EMG using intramuscular electrodes reveals non-linear fatigability characteristics in persons with chronic low back pain. J Electromyogr Kinesiol. 2013; 23: 70-7.

22. Asplund C, Webb C and Barkdull T. Neck and back pain in bicycling. Curr Sports Med Rep. 2005; 4: 271-4.

23. Bressel E and Larson BJ. Bicycle seat designs and their effect on pelvic angle, trunk angle, and comfort. Med Sci Sports Exerc. 2003; 35: 327-32.

24. Sauer JL, Potter JJ, Weisshaar CL, Ploeg HL and Thelen DG. Biodynamics. Influence of gender, power, and hand position on pelvic motion during seated cycling. Med Sci Sports Exerc. 2007; 39: 2204-11.

25. Gade VK and Wilson SE. Position sense in the lumbar spine with torso flexion and loading. J Appl Biomech. 2007; 23: 93-102. 26. Stone $\mathrm{C}$ and Hull ML. The effect of rider weight on rider-induced loads during common cycling situations. $J$ Biomech. 1995; 28: 365-75.

27. Carpes FP, Rossato M, Faria IE and Bolli Mota C. Bilateral pedaling asymmetry during a simulated 40-km cycling timetrial. J Sports Med Phys Fitness. 2007; 47: 51-7.

28. Nadler SF, Malanga GA, Feinberg JH, Prybicien M, Stitik TP and DePrince M. Relationship between hip muscle imbalance and occurrence of low back pain in collegiate athletes: a prospective study. Am J Phys Med Rehabil. 2001; 80: 572-7.

29. Wallwork TL, Stanton WR, Freke M and Hides JA. The effect of chronic low back pain on size and contraction of the lumbar multifidus muscle. Man Ther. 2009; 14: 496-500.

\section{Elisandro de Assis Martins}

Endereço para correspondência - Rua: Barão do Triunfo, n 1623, Bairro: Fátima, CEP: 97015-070, Santa Maria, RS, Brasil.

E-mail: Elisandro.martins@gmail.com

Lattes: http://lattes.cnpq.br/2345350159354115

Frederico Dagnese - frederico.dagnese@gmail.com

Álvaro Sosa Machado - alvaro@alunos.unipampa.edu.br

Emmanuel Souza da Rocha - emmarocha@gmail.com

Carlos Bolli Mota - bollimota@gmail.com

Felipe Pivetta Carpes - carpes@unipampa.edu.br

\section{Enviado em 02 de junho de 2014. Aceito em 12 de agosto de 2015.}


